\title{
ALGUMAS REFLEXÕES SOBRE O ENSINO MEDIADO POR COMPUTADORES
}

\section{Cíntia Maria Basso}

\section{INTRODUÇÃO}

As rápidas mudanças ocorridas na sociedade e o grande volume de informações estão refletindo-se no ensino, exigindo, desta forma, que a escola não seja uma mera transmissora de conhecimentos, mas que seja um ambiente estimulante, que valorize a invenção e a descoberta, que possibilite à criança percorrer o conhecimento de maneira mais motivada, crítica e criativa, que proporcione um movimento de parceria, de trocas de experiências, de afetividade no ato de aprender e desenvolver o pensamento crítico reflexivo.

A integração dos computadores nas escolas, vista como uma dinâmica de interação, como um ambiente rico para a mediação entre sujeitos, oferece condições para envolver as crianças e estimular a investigação, além de possibilitar paradas e retornos para interpretação, análise, atendendo o ritmo de cada criança.

Enfatiza-se, através da informática educativa, a descoberta e a invenção, possibilitando a formação de alunos capazes de construir seu próprio conhecimento, tornando-se pesquisadores autônomos à medida que descobrem novas áreas de seu interesse. O professor precisa transformar-se em um guia, capaz de estimular seus alunos a navegarem pelo conhecimento, fazerem suas próprias descobertas e desenvolverem sua capacidade de observar, pensar, comunicar e criar.

Neste artigo, sistematizarei alguns pressupostos básicos das teorias do desenvolvimento de Piaget, Wallon e Vygotsky. Após, farei algumas reflexões sobre a integração de computadores nas escolas e as contribuições da teoria do desenvolvimento de Vygotsky, a qual explica a interatividade e a construção coletiva do conhecimento em um meio sócio-histórico cultural, propiciada pela mediação aluno/aluno; aluno/professor; aluno/computador; enfim, aluno/conhecimento.

\section{TEORIA DO DESENVOLVIMENTO DE JEAN PIAGET}

Formado em Biologia, Piaget especializou-se nos estudos do conhecimento humano, concluindo que, assim como os organismos vivos podem adaptar-se geneticamente a um novo meio, existe também uma relação evolutiva entre o sujeito e o seu meio, ou seja, a criança reconstrói suas ações e idéias quando se relaciona com novas experiências ambientais. Para ele, a criança constrói sua realidade como um ser humano singular, situação em que o cognitivo está em supremacia em relação ao social e o afetivo. 
Na perspectiva construtivista de Piaget, o começo do conhecimento é a ação do sujeito sobre o objeto, ou seja, o conhecimento humano se constrói na interação homem-meio, sujeito-objeto. Conhecer consiste em operar sobre o real e transformá-lo a fim de compreendê-lo, é algo que se dá a partir da ação do sujeito sobre o objeto de conhecimento. As formas de conhecer são construídas nas trocas com os objetos, tendo uma melhor organização em momentos sucessivos de adaptação ao objeto. A adaptação ocorre através da organização, sendo que o organismo discrimina entre estímulos e sensações, selecionando aqueles que irá organizar em alguma forma de estrutura. A adaptação possui dois mecanismos opostos, mas complementares, que garantem o processo de desenvolvimento: a assimilação e a acomodação. Segundo Piaget, o conhecimento é a equilibração/reequilibração entre assimilação e acomodação, ou seja, entre os indivíduos e os objetos do mundo.

A assimilação é a incorporação dos dados da realidade nos esquemas disponíveis no sujeito, é o processo pelo qual as idéias, pessoas, costumes são incorporadas à atividade do sujeito. A criança aprende a língua e assimila tudo o que ouve, transformando isso em conhecimento seu. A acomodação é a modificação dos esquemas para assimilar os elementos novos, ou seja, a criança que ouve e começa a balbuciar em resposta à conversa ao seu redor gradualmente acomoda os sons que emite àqueles que ouve, passando a falar de forma compreensível.

Segundo FARIA (1998), os esquemas são uma necessidade interna do indivíduo. Os esquemas afetivos levam à construção do caráter, são modos de sentir que se adquire juntamente às ações exercidas pelo sujeito sobre pessoas ou objetos. Os esquemas cognitivos conduzem à formação da inteligência, tendo a necessidade de serem repetidos (a criança pega várias vezes o mesmo objeto). Outra propriedade do esquema é a ampliação do campo de aplicação, também chamada de assimilação generalizadora (a criança não pega apenas um objeto, pega outros que estão por perto). Através da discriminação progressiva dos objetos, da capacidade chamada de assimilação recognitiva ou reconhecedora, a criança identifica os objetos que pode ou não pegar, que podem ou não dar algum prazer à ela.

FARIA (op.cit.) salienta que os fatores responsáveis pelo desenvolvimento, segundo Piaget, são: maturação; experiência física e lógico-matemática; transmissão ou experiência social; equilibração; motivação; interesses e valores; valores e sentimentos. A aprendizagem é sempre provocada por situações externas ao sujeito, supondo a atuação do sujeito sobre o meio, mediante experiências. A aprendizagem será a aquisição que ocorre em função da experiência e que terá caráter imediato. Ela poderá ser: experiência física comporta ações diferentes em função dos objetos e consiste no desenvolvimento de ações sobre esses objetos para descobrir as propriedades que são abstraídas deles próprios, é o produto das ações do sujeito sobre o objeto; e experiência lógico-matemática - o sujeito age sobre os objetos de modo a descobrir propriedades e relações que são abstraídas de suas próprias ações, ou seja, resulta da coordenação das ações que o sujeito exerce sobre os objetos e da tomada de consciência dessa coordenação. Essas duas experiências estão inter- 
relacionadas, uma é condição para o surgimento da outra.

Para que ocorra uma adaptação ao seu ambiente, o indivíduo deverá equilibrar uma descoberta, uma ação com outras ações. A base do processo de equilibração está na assimilação e na acomodação, isto é, promove a reversibilidade do pensamento, é um processo ativo de auto-regulação. Piaget afirma que, para a criança adquirir pensamento e linguagem, deve passar por várias fases de desenvolvimento psicológico, partindo do individual para o social. Segundo ele, o falante passa por pensamento autístico, fala egocêntrica para atingir o pensamento lógico, sendo o egocentrismo o elo de ligação das operações lógicas da criança. No processo de egocentrismo, a criança vê o mundo a partir da perspectiva pessoal, assimilando tudo para si e ao seu próprio ponto de vista, estando o pensamento e a linguagem centrados na criança.

Para Piaget, o desenvolvimento mental dá-se espontaneamente a partir de suas potencialidades e da sua interação com o meio. O processo de desenvolvimento mental é lento, ocorrendo por meio de graduações sucessivas através de estágios: período da inteligência sensório-motora; período da inteligência préoperatória; período da inteligência operatória-concreta; e período da inteligência operatório-formal.

\section{TEORIA DO DESENVOLVIMENTO DE HENRY WALLON}

A criança, para Wallon, é essencialmente emocional e gradualmente vai constituindo-se em um ser sócio-cognitivo. O autor estudou a criança contextualizada, como uma realidade viva e total no conjunto de seus comportamentos, suas condições de existência.

Segundo GALVÃO (2000), Wallon argumenta que as trocas relacionais da criança com os outros são fundamentais para o desenvolvimento da pessoa. As crianças nascem imersas em um mundo cultural e simbólico, no qual ficarão envolvidas em um "sincretismo subjetivo", por pelo menos três anos. Durante esse período, de completa indiferenciação entre a criança e o ambiente humano, sua compreensão das coisas dependerá dos outros, que darão às suas ações e movimentos formato e expressão.

Antes do surgimento da linguagem falada, as crianças comunicam-se e constituem-se como sujeitos com significado, através da ação e interpretação do meio entre humanos, construindo suas próprias emoções, que é seu primeiro sistema de comunicação expressiva. Estes processos comunicativos-expressivos acontecem em trocas sociais como a imitação. Imitando, a criança desdobra, lentamente, a nova capacidade que está a construir (pela participação do outro ela se diferenciará dos outros) formando sua subjetividade. Pela imitação, a criança expressa seus desejos de participar e se diferenciar dos outros constituindo-se em sujeito próprio.

Wallon propõe estágios de desenvolvimento, assim como Piaget, porém, ele não é 
adepto da idéia de que a criança cresce de maneira linear. O desenvolvimento humano tem momentos de crise, isto é, uma criança ou um adulto não são capazes de se desenvolver sem conflitos. A criança se desenvolve com seus conflitos internos e, para ele, cada estágio estabelece uma forma específica de interação com o outro, é um desenvolvimento conflituoso.

No início do desenvolvimento existe uma preponderância do biológico e após o social adquire maior força. Assim como Vygotsky, Wallon acredita que o social é imprescindível. A cultura e a linguagem fornecem ao pensamento os elementos para evoluir, sofisticar. A parte cognitiva social é muito flexível, não existindo linearidade no desenvolvimento, sendo este descontínuo e, por isso, sofre crises, rupturas, conflitos, retrocessos, como um movimento que tende ao crescimento.

De acordo com GALVÃO (op.cit.), no primeiro ano de vida, a criança interage com o meio regida pela afetividade, isto é, o estágio impulsivo-emocional, definido pela simbiose afetiva da criança em seu meio social. A criança começa a negociar, com seu mundo sócio-afetivo, os significados próprios, via expressões tônicas. As emoções intermediam sua relação com o mundo.

Do estágio sensório-motor ao projetivo (1 a 3 anos), predominam as atividades de investigação, exploração e conhecimento do mundo social e físico. No estágio sensório-motor, permanece a subordinação a um sincretismo subjetivo (a lógica da criança ainda não está presente). Neste estágio predominam as relações cognitivas da criança com o meio. Wallon identifica o sincretismo como sendo a principal característica do pensamento infantil. Os fenômenos típicos do pensamento sincrético são: fabulação, contradição, tautologia e elisão.

Na gênese da representação, que emerge da imitação motora-gestual ou motricidade emocional, as ações da criança não mais precisarão ter origem na ação do outro, ela vai "desprender-se" do outro, podendo voltar-se para a imitação de cenas e acontecimentos, tornando-se habilitada à representação da realidade. Este salto qualitativo da passagem do ato imitativo concreto e a representação é chamado de simulacro. No simulacro, que é a imitação em ato, forma-se uma ponte entre formas concretas de significar e representar e níveis semióticos de representação. Essa é a forma pela qual a criança se desloca da inteligência prática ou das situações para a inteligência verbal ou representativa.

Dos 3 aos 6 anos, no estágio personalístico, aparece a imitação inteligente, a qual constrói os significados diferenciados que a criança dá para a própria ação. Nessa fase, a criança está voltada novamente para si própria. Para isso, a criança coloca-se em oposição ao outro num mecanismo de diferenciar-se. A criança, mediada pela fala e pelo domínio do "meu/minha", faz com que as idéias atinjam o sentimento de propriedade das coisas. A tarefa central é o processo de formação da personalidade. Aos 6 anos a criança passa ao estágio categorial trazendo avanços na inteligência. No estágio da adolescência, a criança volta-se a questões pessoais, morais, predominando a afetividade. Ainda conforme GALVÃO, é nesse estágio que se intensifica a realização das diferenciações necessárias à redução do sincretismo do pensamento. Esta redução do sincretismo e o estabelecimento da função categorial dependem do meio cultural 
no qual está inserida a criança.

\section{TEORIA DO DESENVOLVIMENTO DE LEV S. VYGOTSKY}

Para Vygotsky, a criança nasce inserida num meio social, que é a família, e é nela que estabelece as primeiras relações com a linguagem na interação com os outros. Nas interações cotidianas, a mediação (necessária intervenção de outro entre duas coisas para que uma relação se estabeleça) com o adulto acontece espontaneamente no processo de utilização da linguagem, no contexto das situações imediatas.

Essa teoria apóia-se na concepção de um sujeito interativo que elabora seus conhecimentos sobre os objetos, em um processo mediado pelo outro. 0 conhecimento tem gênese nas relações sociais, sendo produzido na intersubjetividade e marcado por condições culturais, sociais e históricas.

Segundo Vygotsky, o homem se produz na e pela linguagem, isto é, é na interação com outros sujeitos que formas de pensar são construídas por meio da apropriação do saber da comunidade em que está inserido o sujeito. A relação entre homem e mundo é uma relação mediada, na qual, entre o homem e o mundo existem elementos que auxiliam a atividade humana. Estes elementos de mediação são os signos e os instrumentos. O trabalho humano, que une a natureza ao homem e cria, então, a cultura e a história do homem, desenvolve a atividade coletiva, as relações sociais e a utilização de instrumentos. Os instrumentos são utilizados pelo trabalhador, ampliando as possibilidades de transformar a natureza, sendo assim, um objeto social.

Os signos também auxiliam nas ações concretas e nos processos psicológicos, assim como os instrumentos. A capacidade humana para a linguagem faz com que as crianças providenciem instrumentos que auxiliem na solução de tarefas difíceis, planejem uma solução para um problema e controlem seu comportamento. Signos e palavras são para as crianças um meio de contato social com outras pessoas. Para Vygotsky, signos são meios que auxiliam/facilitam uma função psicológica superior (atenção voluntária, memória lógica, formação de conceitos, etc.), sendo capazes de transformar o funcionamento mental. Desta maneira, as formas de mediação permitem ao sujeito realizar operações cada vez mais complexas sobre os objetos.

Segundo Vygotsky, ocorrem duas mudanças qualitativas no uso dos signos: o processo de internalização e a utilização de sistemas simbólicos. A internalização é relacionada ao recurso da repetição onde a criança apropria-se da fala do outro, tornando-a sua. Os sistemas simbólicos organizam os signos em estruturas, estas são complexas e articuladas. Essas duas mudanças são essenciais e evidenciam o quanto são importantes as relações sociais entre os sujeitos na construção de processos psicológicos e no desenvolvimento dos processos mentais superiores. Os signos internalizados são compartilhados pelo grupo social, permitindo o aprimoramento da interação social e a comunicação entre os sujeitos. As funções psicológicas superiores aparecem, no desenvolvimento da criança, duas vezes: primeiro, no nível social (entre pessoas, no nível interpsicológico) e, depois, no 
nível individual (no interior da criança, no nível intrapsicológico). Sendo assim, o desenvolvimento caminha do nível social para o individual.

Como visto, exige-se a utilização de instrumentos para transformar a natureza e, da mesma forma, exige-se o planejamento, a ação coletiva, a comunicação social. Pensamento e linguagem associam-se devido à necessidade de intercâmbio durante a realização do trabalho. Porém, antes dessa associação, a criança tem a capacidade de resolver problemas práticos (inteligência prática), de fazer uso de determinados instrumentos para alcançar determinados objetivos. Vygotsky chama isto de fase pré-verbal do desenvolvimento do pensamento e uma fase pré-intelectual no desenvolvimento da linguagem.

Por volta dos 2 anos de idade, a fala da criança torna-se intelectual, generalizante, com função simbólica, e o pensamento torna-se verbal, sempre mediado por significados fornecidos pela linguagem. Esse impulso é dado pela inserção da criança no meio cultural, ou seja, na interação com adultos mais capazes da cultura que já dispõe da linguagem estruturada. Vygotsky destaca a importância da cultura; para ele, o grupo cultural fornece ao indivíduo um ambiente estruturado onde os elementos são carregados de significado cultural.

Os significados das palavras fornecem a mediação simbólica entre o indivíduo e o mundo, ou seja, como diz VYGOTSKY (1987), é no significado da palavra que a fala e o pensamento se unem em pensamento verbal. Para ele, o pensamento e a linguagem iniciam-se pela fala social, passando pela fala egocêntrica, atingindo a fala interior que é pensamento reflexivo.

A fala egocêntrica emerge quando a criança transfere formas sociais e cooperativas de comportamento para a esfera das funções psíquicas interiores e pessoais. No início do desenvolvimento, a fala do outro dirige a ação e a atenção da criança. Esta vai usando a fala de forma a afetar a ação do outro. Durante esse processo, ao mesmo tempo que a criança passa a entender a fala do outro e a usar essa fala para regulação do outro, ela começa a falar para si mesma. A fala para si mesma assume a função auto-reguladora e, assim, a criança torna-se capaz de atuar sobre suas próprias ações por meio da fala. Para Vygotsky, o surgimento da fala egocêntrica indica a trajetória da criança: o pensamento vai dos processos socializados para os processos internos.

A fala interior, ou discurso interior, é a forma de linguagem interna, que é dirigida ao sujeito e não a um interlocutor externo. Esta fala interior, se desenvolve mediante um lento acúmulo de mudanças estruturais, fazendo com que as estruturas de fala que a criança já domina, tornem-se estruturas básicas de seu próprio pensamento. A fala interior não tem a finalidade de comunicação com outros, portanto, constitui-se como uma espécie de "dialeto pessoal", sendo fragmentada, abreviada.

A relação entre pensamento e palavra acontece em forma de processo, constituindo-se em um movimento contínuo de vaivém do pensamento para a palavra e vice-versa. Esse processo passa por transformações que, em si mesmas, podem ser consideradas um desenvolvimento no sentido funcional. 
VYGOTSKY (op.cit.) diz que o pensamento nasce através das palavras. É apenas pela relação da criança com a fala do outro em situações de interlocução, que a criança se apropria das palavras, que, no início, são sempre palavras do outro. Por isso, é fundamental que as práticas pedagógicas trabalhem no sentido de esclarecer a importância da fala no processo de interação com o outro.

Segundo VYGOTSKY (1989), a aprendizagem tem um papel fundamental para o desenvolvimento do saber, do conhecimento. Todo e qualquer processo de aprendizagem é ensino-aprendizagem, incluindo aquele que aprende, aquele que ensina e a relação entre eles. Ele explica esta conexão entre desenvolvimento e aprendizagem através da zona de desenvolvimento proximal (distância entre os níveis de desenvolvimento potencial e nível de desenvolvimento real), um "espaço dinâmico" entre os problemas que uma criança pode resolver sozinha (nível de desenvolvimento real) e os que deverá resolver com a ajuda de outro sujeito mais capaz no momento, para em seguida, chegar a dominá-los por si mesma (nível de desenvolvimento potencial).

\section{O INTERACIONISMO E A MEDIAÇÃO DAS NOVAS TECNOLOGIAS NA PRODUÇÃO DO CONHECIMENTO ESCOLAR}

A integração de novas tecnologias nas escolas precisa dar ênfase na importância do contexto sócio-histórico-cultural em que os alunos vivem e a aspectos afetivos que suas linguagens representam. O uso de computadores como um meio de interação social, onde o conflito cognitivo, os riscos e desafios e o apoio recíproco entre pares está presente, é um meio de desenvolver culturalmente a linguagem e propiciar que a criança construa seu próprio conhecimento. Segundo RICHTER (2000), as crianças precisam correr riscos e desafios para serem bem sucedidas em seu processo de ensino-aprendizagem, produzindo e interpretando a linguagem que está além das certezas que já tem sobre a língua.

Vygotsky valoriza o trabalho coletivo, cooperativo, ao contrário de Piaget, que considera a criança como construtora de seu conhecimento de forma individual. $\mathrm{O}$ ambiente computacional proporciona mudanças qualitativas na zona de desenvolvimento proximal do aluno, os quais não acontecem com muita freqüência em salas de aula "tradicionais". A colaboração entre crianças pressupõe um trabalho de parceria conjunta para produzir algo que não poderiam produzir individualmente.

A zona de desenvolvimento proximal, comentada anteriormente, possibilita a interação entre sujeitos, permeada pela linguagem humana e pela linguagem da máquina, força o desempenho intelectual porque faz os sujeitos reconhecerem e coordenarem os conflitos gerados por uma situação problema, construindo um conhecimento novo a partir de seu nível de competência que se desenvolve sob a influência de um determinado contexto sócio-histórico-cultural. Wallon também acredita que o processo de construção do conhecimento passa por conflitos, momentos de crises e rupturas.

A colaboração em um ambiente computacional torna-se visível e constante, vinda do ambiente livre e aberto ao diálogo, da troca de idéias, onde a fala tem papel 
fundamental na aplicação dos conteúdos. A interação entre o parceiro sentado ao lado, entre o computador, os conhecimentos, os professores que seguem o percurso da construção do conhecimento, e até mesmo os outros colegas que, apesar de estarem envolvidos com sua procura, pesquisa, navegação, prestam atenção ao que acontece em sua volta, gera uma grande equipe que busca a produção do conhecimento constantemente. Através disso tudo a criança ganhará mais confiança para produzir algo, criar mais livremente, sem medo dos erros que possa cometer, aumentando sua auto-confiança, sua auto-estima, na aceitação de críticas, discussões de um trabalho feito pelos seus próprios pares.

As novas tecnologias não substituem o professor, mas modificam algumas de suas funções. O professor transforma-se agora no estimulador da curiosidade do aluno por querer conhecer, por pesquisar, por buscar as informações. Ele coordena o processo de apresentação dos resultados pelos alunos, questionando os dados apresentados, contextualizando os resultados, adaptando-os para a realidade dos alunos. O professor pode estar mais próximo dos alunos, receber mensagens via e-mail com dúvidas, passar informações complementares para os alunos, adaptar a aula para o ritmo de cada um. Assim sendo, o processo de ensino-aprendizagem ganha um dinamismo, inovação e poder de comunicação até agora pouco utilizados.

As crianças também podem utilizar o E-mail para trocar informações, dúvidas com seus colegas e professores, tornando o aprendizado mais cooperativo. $O$ uso do correio eletrônico proporciona uma rica estratégia para aumentar as habilidades de comunicação, fornecendo ao aluno oportunidades de acesso a culturas diversas, aperfeiçoando o aprendizado em várias àreas do conhecimento.

O uso da Internet, ou seja, o hiperespaço, é caracterizado como uma forma de comunicação que propicia a formação de um contexto coletivizado, resultado da interação entre participantes. Conectar-se é sinônimo de interagir e compartilhar no coletivo. A navegação em sites transforma-se num jogo discursivo em que significados, comportamentos e conhecimentos são criticados, negociados e redefinidos. Este jogo comunicativo tende a reverter o "monopólio" da fala do professor em sala de aula.

\section{CONSIDERAÇÕES FINAIS}

Desta forma, a implantação de novas tecnologias na escola deve ser mediada por atitudes pedagógicas que permitam formar o cidadão que ocupará seu lugar neste novo espaço. As tecnologias, dentro de um projeto pedagógico inovador, facilitam e estimulam o processo de ensino-aprendizagem. Neste sentido, a hipermídia introduz a interatividade no aprendizado, propiciando o diálogo ativo com o mundo do conhecimento, apresentando informações através de um contínuo canal de escolhas individuais. Ela nos permite navegar e determinar os caminhos a seguir de acordo com nossos interesses e nosso próprio ritmo. Enfim, é descoberta, é pesquisa, é conhecimento, é participação, sensibilizando assim, para novos assuntos, novas informações, diminuindo a rotina e nos ligando com o mundo, trocando experiências entre si, conhecendo-se, comunicando-se, enfim, educando-se. 
RICHTER (op.cit.), ao referir-se ao interacionismo, observa a necessidade de se dar ênfase à interação conversacional entre as crianças, para terem, com isso, acesso a input significativo e compreensivo (agir sobre uma mensagem para verificar o que entendeu sobre determinado assunto), com vistas à chegarem à negociação de sentidos (expressar e esclarecer intenções, pensamentos, opiniões). Através dessa negociação de sentidos, a criança poderá produzir uma nova mensagem sobre o que realmente entendeu (output).

Portanto, é no ensino fundamental que deve começar o processo de conscientização de professores e alunos no sentido de buscar e usar a informação, na direção do enriquecimento intelectual, na auto-instrução. Isso significa que não podemos admitir, nos tempos de hoje, um professor que seja um mero repassador de informações. O que se exige, é que ele seja um criador de ambientes de aprendizagem, parceiro e colaborador no processo de construção do conhecimento, que se atualize continuamente.

\section{BIBLIOGRAFIA :}

CASTORINA, JOSÉ ANTÔNIO. "O debate Piaget-Vygotsky: a busca de um critério para sua avaliação". In: Piaget-Vygotsky: novas contribuições para o debate. São Paulo: Ática, 1988. pp.7-50

CORRÊA, MÁRCIA AMARAL. "As relações existentes entre os pressupostos teóricos da epistemologia genética piagetiana e a utilização da produção textual no espaço escolar". In: Ciências e Letras. Porto Alegre, N.26, pp.79-96, jul./dez. 1999.

DAVIS, CLÁUDIA. "O construtivismo de Piaget e o sócio-interacionismo de Vygotsky". In: Anais: I Seminário Internacional de Alfabetização \& Educação Científica. Ijuí: UNIJUÍ, 1993.

FARIA, ANÁLIA RODRIGUES DE. Desenvolvimento da criança e do adolescente segundo Piaget. 4ª . ed. São Paulo : Ática, 1998. Capítulos 1 e 3. GALVÃO, IZABEL. Henri Wallon: uma concepção dialética do desenvolvimento infantil. 7ª.ed. Petrópolis, RJ : Vozes, 2000.(Educação e conhecimento). $134 \mathrm{p}$.

LA TAILLE, YVES DE; OLIVEIRA, MARTA KOHL DE. Piaget, Vygotsky, Wallon : teorias psicogenéticas em discussão. São Paulo : Summus.

ANA LUÍSA SMOLKA, MARIA CECILIA RAFAEL DE GÓES(orgs). $\boldsymbol{A}$ linguagem e o outro no espaço escolar: Vygotsky e a construção do conhecimento. 4.ed. Campinas :Papirus, 1995. (Coleção Magistério: formação e trabalho pedagógico). 177p.

MOLL, LUIS C. Vygotsky e a educação: implicações pedagógicas da psicologia sócio- histórica. Porto Alegre : Artes Médicas, 1996.

OLIVEIRA, MARTA KOHL DE. "O pensamento e a linguagem na perspectiva sócio-histórica". In: Anais: I Seminário Internacional de Alfabetização \& Educação Científica. Ijuí : UNIJUÍ, 1993.

Pensar a educação:

Vygotsky. In: Piaget- Vygotsky: novas contribuições contribuições de São Paulo:Ática, 1988. pp. 51-83. 
desenvolvimento, um processo sócio- histórico. Scipione. Série Pensamento e Ação no Magistério.

PRETTO, NELSON DE LUCA. "A educação num mundo de comunicação". In: Uma escola com/sem futuro. Campinas: Papirus, 1996. (Coleção Magistério: Formação e Trabalho Pedagógico). pp. 97-120.

RICHTER, MARCOS GUSTAVO. Ensino do português e interatividade. Santa Maria: Ed. UFSM, 2000.136 p.

SCHAFFER, MARGARETH. "O construtivismo-interacionista e as novas intersecções". In: Anais: I Seminário Internacional de Alfabetização \& Educação Científica. Ijuí : UNIJUÍ, 1993.

MARIA CECÍLIA GÓES; ANA LUIZA SMOLKA (orgs.) A significação nos espaços educacionais: interação social e subjetivação. Campinas: Papirus, 1997. (Coleção Magistério: Formação e Trabalho Pedagógico). 179 p.

SMOLKA, ANA LUIZA B. et al. Leitura e desenvolvimento da linguagem. Porto Alegre: Mercado Aberto, 1989. (Série Novas Perspectivas). 69p.

TAJRA, SANMYA FEITOSA. Informática na educação: novas ferramentas pedagógicas para o professor da atualidade. 2ª .ed. São Paulo: Érica, 2000. $143 \mathrm{p}$.

VERÍSSIMO, MARA RÚBIA ALVES MARQUES. "O materialismo histórico e dialético nas abordagens de Vygotsky e Wallon acerca do pensamento e da linguagem". In: Educação e filosofia, v.10, n.19, p.129-143, jan./jun. 1996.

VYGOTSKY, LEV S. Pensamento e linguagem. São Paulo: Martins Fontes, 1987. 135 p. (Coleção Psicologia e Pedagogia).

VYGOTSKY, LEV S. A formação social da mente: o desenvolvimento dos processos psicológicos superiores. 3ª.ed. São Paulo: Martins Fontes, 1989. 168p. (Coleção Psicologia e Pedagogia. Nova Série). 